\title{
RIZOBACTÉRIAS NO CONTROLE DA MANCHA ANGULAR DO ALGODOEIRO
}

\author{
Rhizobacteria to control cotton bacterial blight
}

\author{
Alessandra Keiko Nakasone Ishida ${ }^{1}$, Ricardo Magela de Souza² ${ }^{2}$, Mário Lúcio Vilela de Resende ${ }^{3}$, \\ Ana Beatriz Zacaroni ${ }^{4}$, Carla Heloísa Vilas Bôas ${ }^{4}$, Jorge Teodoro de Souza ${ }^{5}$
}

\begin{abstract}
RESUMO
Avaliou-se o potencial de rizobactérias na indução de resistência do algodoeiro à Xanthomonas axonopodis pv. malvacearum. Após o isolamento das rizobactérias, foram selecionados os isolados capazes de reduzir os sintomas da mancha angular bacteriana em casa de vegetação, os quais foram aplicados espacialmente separados do patógeno desafiador. Os melhores isolados foram testados quanto à capacidade de reduzir os sintomas da ramulose e da murcha de Verticillium e de inibir diretamente os patógenos in vitro. Do total de 123 isolados de rizobactérias foram selecionados cinco, L2-1 (Bacillus cereus), MT5-6 (Bacillus cereus), L2-2 (Achromobacter xylosoxidans), MT5-5 (Bacillus cereus) e MT5-11 (Brevibacterium sp.), os quais apresentaram controle da mancha angular acima de $40 \%$, em relação à testemunha. Nenhum isolado reduziu a severidade da ramulose e da murcha de Verticillium em relação à testemunha, nem apresentou efeito inibitório direto in vitro a X. axonopodis pv. malvacearum e Colletotrichum gossypii var. cephalosporioides. Para V. dahliae, apenas o isolado L2-1 apresentou efeito inibitório.
\end{abstract}

Termos para indexação: Gossypium hirsutum, Xanthomonas axonopodis pv. malvacearum, Colletotrichum gossypii var. cephalosporioides, Verticillium dahliae, resistência induzida.

\begin{abstract}
The potential of rhizobacteria was evaluated for resistance induction against Xanthomonas axonopodis pv. malvacearum. After isolation, the rhizobacteria were screened for the reduction of angular leaf spot severity under greenhouse conditions. They were spatially separated from the challenging pathogen. The best isolates were tested for the capacity to reduce ramulose and Verticillium wilt severity and directly inhibit pathogens in vitro. From a total of 123 rhizobacterial isolates, five were selected, L2-1 (Bacillus cereus), MT5-6 (Bacillus cereus), L2-2 (Achromobacter xylosoxidans), MT5-5 (Bacillus cereus) and MT5-11 (Brevibacterium sp.), which showed angular leaf spot control above $40 \%$ as compared to the control. The tested isolates neither reduced the severity of ramulose and verticillium wilt compared to the control nor showed in vitro direct inhibition to $X$. axonopodis pv. malvacearum and Colletotrichum gossypii var. cephalosporioides. For V. dahliae, only isolate L2-1 showed direct inhibition.
\end{abstract}

Index terms: Gossypium hirsutum, Xanthomonas axonopodis pv. malvacearum, Colletotrichum gossypii var. cephalosporioides, Verticillium dahliae, induced resistance.

(Recebido em 22 de setembro de 2006 e aprovado em 5 de fevereiro de 2007)

\section{INTRODUÇÃO}

A cultura do algodão no Brasil vem aumentando significativamente em área e produção, especialmente na região Centro-Oeste, principal produtora do país, responsável por $63,8 \%$ da produção nacional (CASSETARI NETO \& MACHADO, 2000). O alto investimento em tecnologia e principalmente o plantio em extensas áreas, requerem medidas eficientes no que diz respeito aos fatores limitantes como as doenças, para obtenção de índices satisfatórios de produtividade. Dentre as doenças que ocorrem no algodão, a mancha angular, Xanthomonas axonopodis pv. malvacearum (Smith) (VAUTERIN et al., 1995) (Xam), a ramulose (Colletotrichum gossypium var. cephalosporioides A. S. Costa) estão disseminadas, praticamente, em todas as áreas de cultivo no país. A murcha de Verticillium (Verticillium dahliae Kleb.) ocorre nos Estados do Paraná, São Paulo e Minas Gerais, em solos argilosos, com predominância de alta matéria orgânica (JULIATTI \& RUANO, 1997). As primeiras observações

\footnotetext{
${ }^{1}$ Doutora - Pavilhão de Pesquisa/Fitopatologia - Embrapa Amazônia Oriental - Travessa Doutor Enéas Pinheiro, s/n - Cx. P 48 - 66095-100 - Belém, PA keiko@cpatu.embrapa.br

2Doutor, Professor Associado - Departamento de Fitopatologia/DFP - Universidade Federal de Lavras/UFLA - Cx. P 3037 - $37200-000$ - Lavras, MG rmagelas@ufla.br - Bolsista CNPq

${ }^{3}$ PhD, Professor Associado - Departamento de Fitopatologia/DFP - Universidade Federal de Lavras/UFLA - Cx. P 3037 - $37200-000$ - Lavras, MG mlucio@ufla.br - Bolsista CNPq

${ }^{4}$ Engenheiras Agrônomas - Departamento de Fitopatologia/DFP - Universidade Federal de Lavras/UFLA - Cx. P. 3037 - $37200-000$ - Lavras, MG ana_zacaroni@yahoo.com.br; c13h2000@yahoo.com.br - Bolsista inciação científica CNPq

${ }^{5}$ Doutor, Professor Adjunto - Centro de Ciências Agrárias, Ambientais e Biológicas/CCAAB - Universidade Federal do Recôncavo da Bahia/UFRB 44380-000 - Cruz das Almas, BA - jorgetdes@yahoo.com.br
} 
de ocorrência severa destas doenças foram feitas em genótipos altamente susceptíveis. A ramulose e a mancha angular ocorrem com maior severidade sob condições de alta umidade, temperatura elevada e dias nublados (CASSETARI NETO \& MACHADO, 2000; CIA \& SALGADO, 1997), enquanto a murcha de Verticillium é mais severa sob temperaturas mais baixas, $\left(18-22^{\circ} \mathrm{C}\right)$, tanto em linhagens tolerantes como susceptíveis, independente do grau de agressividade do patógeno (CIA \& SALGADO, 1997).

A resistência induzida é definida como o aumento da capacidade defensiva da planta contra amplo espectro de patógenos e pragas, adquirida após um estímulo apropriado (KNOESTER et al., 1999; LOON et al., 1998; RAMAMOORTHY et al., 2001) e baseia-se no reconhecimento de um invasor e subseqüentes eventos de transdução de sinal que levam à ativação das defesas (MAUCH-MANI \& MÉTRAUX, 1998).

O estudo da resistência de plantas induzidas por rizobactérias, para controle de doenças, tem mostrado resultados promissores em várias culturas contra fungos, bactérias e vírus (HOFFLAND et al., 1996; JETIYANON \& KLOEPPER, 2002; SILVA et al., 2004a,b). Além do fator ambiental, com a utilização de produtos menos tóxicos ao meio ambiente, a proteção contra amplo espectro de patógenos faz da resistência induzida uma opção adicional para o agricultor, sendo complementar à resistência genética e ao uso de fungicidas contra um amplo espectro de patógenos. Se integrada, apropriadamente, em programas de manejo de plantas sadias, ela pode prolongar a vida útil de genes de resistência e dos fungicidas usados atualmente.

Assim, objetivou-se, neste trabalho, selecionar rizobactérias capazes de induzir resistência sistêmica a Xam em algodão; avaliar o efeito destas rizobactérias no controle da ramulose e da murcha de Verticillium em casa de vegetação e no crescimento in vitro de Xam, C. gossypium var. cephalosporioides e $V$. dahliae.

\section{MATERIALE MÉTODOS}

\section{Material vegetal}

Nos ensaios em casa de vegetação, sementes de algodão da cultivar susceptível CNPA Ita 90, previamente desinfestadas com hipoclorito de sódio $1 \%$, por 5 minutos, foram semeadas em vasos de $1,5 \mathrm{~kg}$ de capacidade contendo a mistura de solo, areia e esterco (2:1:1), previamente fumigada com brometo de metila.

\section{Origem e preservação dos isolados de rizobactérias e dos patógenos}

Foram obtidos 123 isolados de rizobactérias de plantas de algodão provenientes dos municípios de Lavras-
MG, Rondonópolis-MT, Primavera do Leste-MT e Campo Verde-MT, dos quais foram selecionados 14 isolados mais eficientes em reduzir os sintomas da mancha angular do algodoeiro (ISHIDA, 2004). O isolado de Xam foi obtido de folhas de algodoeiro apresentando lesões típicas da mancha angular, provenientes da região produtora do município de Rondonópolis-MT. Para o uso experimental, estes isolados, preservados em peptona glicerol a $-80{ }^{\circ} \mathrm{C}$ (LAZO \& GABRIEL, 1987) e em folhas herborizadas (Xam), foram transferidos para o meio 523 (KADO \& HESKETT, 1970), pelo método de estrias paralelas e incubados por 48 h, a $28^{\circ} \mathrm{C}$. Para o preparo da suspensão dos isolados de rizobactérias, as colônias foram diluídas em água de torneira e a concentração ajustada para $\mathrm{A}_{600}=0,50$. A aplicação foi feita pela irrigação do substrato, realizada 2 semanas antes da inoculação do patógeno com $100 \mathrm{~mL}$ da suspensão bacteriana.

A inoculação de Xam foi realizada 36 dias após o plantio, pulverizando-se a face inferior das folhas com suspensão bacteriana, na concentração de $10^{9} \mathrm{UFC} / \mathrm{mL}$. As plântulas foram mantidas por $24 \mathrm{~h}$ antes e depois da inoculação em câmara úmida $\left(28-30^{\circ} \mathrm{C}\right.$ e $90-95 \%$ UR), sendo em seguida levadas para casa de vegetação.

Os fungos Colletotrichum gossypii var. cephalosporioides e Verticillium dahliae, obtidos na micoteca do Laboratório de Patologia de Sementes (DFP - UFLA), foram cultivados em meio batata dextrose agar (BDA), incubados a $25^{\circ} \mathrm{C}$, por 2 semanas. Uma suspensão de $10^{5}$ conídios/mL foi usada para a inoculação. A inoculação de C. gossypii var. cephalosporioides foi realizada pulverizando-se a face inferior das folhas de algodão com suspensão de conídios. As plantas inoculadas foram mantidas por $12 \mathrm{~h}$ depois da inoculação em câmara úmida $\left(20-25^{\circ} \mathrm{C}\right)$, sendo em seguida levadas para casa de vegetação. A inoculação de $V$. dahliae foi realizada através do método de punção na haste (BUGBEE \& PRESLEY, 1967), com seringa plástica e agulha estéreis. As testemunhas foram injetadas com água destilada estéril.

Seleção de rizobactérias com potencial para controlar a mancha angular do algodoeiro em condições de casa de vegetação

Os tratamentos com as rizobactérias foram aplicados 14 dias antes da inoculação de Xam. A severidade da doença foi avaliada aos 7, 14, 21 e 28 dias após a inoculação do patógeno, utilizando-se a escala de Sidhu \& Webster (1977), adaptada. Os valores obtidos serviram de base para o cálculo da área abaixo da curva de progresso da doença (AACPD), proposta por Shaner 
\& Finney (1977). Foi realizada a análise de variância e a comparação das médias, pelo teste de Scott-Knott, a 5\% de probabilidade. O delineamento experimental foi o de blocos casualizados com 15 tratamentos e 4 repetições ( 4 plantas/repetição).

Efeito in vitro de rizobactérias sobre o crescimento de Xanthomonas axonopodis pv. malvacearum, Colletotrichum gossypii var. cephalosporioides e Verticillium dahliae

Um dos critérios para distinguir a resistência induzida de outros mecanismos que podem reduzir a incidência ou severidade da doença é a ausência de efeitos tóxicos do agente indutor sobre o patógeno desafiador (STEINER \& SCHÖNBECK, 1995). Para verificar tal critério, avaliou-se o efeito in vitro dos isolados L2-1, MT5-6, L2-2, MT5-5 e MT5-11 sobre Xam, C. gossypii var. cephalosporioides e V. dahliae. Para isto, placas de Petri contendo meio 523 (KADO \& HESKETT, 1970) foram semeadas com $1 \mathrm{~L}$ da suspensão de rizobactérias, em 2 pontos eqüidistantes, e incubadas por 24 horas, a $28^{\circ} \mathrm{C}$. Em seguida, as placas foram invertidas e em cada tampa adicionou-se $1 \mu \mathrm{L}$ de clorofórmio. Após 30 minutos, as placas foram abertas para a completa evaporação do clorofórmio. As colônias de rizobactérias foram, então, recobertas com uma sobrecamada de $5 \mathrm{~mL}$ de meio 523 semi-sólido fundente, contendo $100 \mu \mathrm{L}$ da suspensão bacteriana de Xam. Após a incubação a $28{ }^{\circ} \mathrm{C}$ por 48 horas, as placas de Petri foram examinadas à procura de zonas de inibição indicativas de antibiose. Para os fungos, utilizou-se $5 \mathrm{~mL}$ de meio BDA semi-sólido fundente, contendo $100 \mathrm{~mL}$ da suspensão de conídios dos fungos testados ( $5 \times 10^{5}$ esporos $/ \mathrm{mL}$ ). As placas de Petri foram incubadas a $25^{\circ} \mathrm{C}$ e examinadas, diariamente, à procura de zonas de inibição indicativas de antibiose até que o crescimento dos fungos tomasse toda a placa. O delineamento experimental foi o inteiramente casualizado com 10 repetições.

Rizobactérias no controle da ramulose e da murcha de Verticillium em algodoeiro em casa de vegetação

Os isolados de rizobactérias L2-1, MT5-5 e MT56 (Bacillus cereus), L2-2 (Achromobacter xylosoxidans), e MT5-11 (Brevibacterium sp.), selecionados por reduzir a severidade da mancha angular do algodoeiro, foram avaliados, no controle da ramulose e da murcha de Verticillium, em casa de vegetação. Para efeito de comparação, utilizou-se o acibenzolar-S-metil (ASM), na dosagem de $10 \mathrm{~g}$ i.a./100L água. Os tratamentos foram aplicados 14 dias antes da inoculação dos patógenos pela irrigação do solo, com $100 \mathrm{~mL}$ de suspensão bacteriana dos isolados e pela pulverização foliar do ASM. Foram realizadas 5 avaliações semanais da severidade das doenças a partir do aparecimento dos primeiros sintomas, (3 semanas após a inoculação do patógeno). A severidade da ramulose foi avaliada por meio da escala de notas de Costa (1941), e da murcha de Verticillium pela escala de Sidhu \& Webster (1977). Os valores obtidos serviram de base para o cálculo da área abaixo da curva de progresso da doença (AACPD), proposta por Shaner \& Finney (1977). Para cada uma das variáveis, foi realizada a análise de variância e a comparação das médias pelo teste de Tukey, a 5\% de probabilidade. O delineamento experimental foi em blocos casualizados, com 7 tratamentos e 4 repetições (6 plantas/repetição).

\section{RESULTADOS E DISCUSSÃO}

Seleção de rizobactérias com potencial para controlar a mancha angular do algodoeiro em condições de casa de vegetação

Os 14 isolados de rizobactérias testados reduziram a severidade da mancha angular do algodoeiro, diferindo significativamente da testemunha. No entanto, destacaram-se os isolados L2-1, MT5-5 e MT5-6 (Bacillus cereus), L2-2 (Achromobacter xylosoxidans), e MT5-11 (Brevibacterium sp.), os quais proporcionaram controle acima de $39 \%$, em relação à testemunha (Tabela 1). O controle da mancha angular do algodoeiro foi relatado pela seleção de bactérias antagonistas, tanto do filoplano (ARYA \& PARASHAR, 2002) como da rizosfera (SAFIYAZOV et al., 1995), pelo tratamento de sementes.

Efeito in vitro de rizobactérias sobre o crescimento de Xanthomonas axonopodis pv. malvacearum, Colletotrichum gossypium var. cephalosporioides e Verticillium dahliae

Nenhum isolado testado inibiu o crescimento de Xam e C. gossypium var. cephalosporioides. Para o fungo Verticillium dahliae, apenas o isolado L2-1 proporcionou halo de inibição do crescimento de $0,35 \mathrm{~cm}$ (Figura 1). De acordo com os resultados, verificou-se que nenhum dos isolados testados apresentou efeito inibidor sobre Xam, indicando que a redução da severidade da mancha angular do algodoeiro, proporcionada por estes isolados em casa de vegetação, não foi obtida por antagonismo direto, podendo estar relacionada à indução de resistência. 
Tabela 1 - Efeito de 14 isolados de rizobactérias, na redução de sintomas da mancha angular do algodoeiro.

\begin{tabular}{lccc}
\hline Tratamentos & AACP D & $\begin{array}{c}\text { Porcentagem de controle em } \\
\text { relação à testemunha }\end{array}$ \\
\hline MT5-5 & 108,31 & C $^{2}$ & 56,05 \\
MT5-6 & 125,03 & C & 49,27 \\
L2-2 & 132,59 & C & 46,21 \\
L2-1 & 139,95 & C & 43,22 \\
MT5-11 & 147,96 & C & 39,97 \\
MT4-19 & 162,33 & B & 34,14 \\
MT5-8 & 166,02 & B & 32,64 \\
MT6-6 & 172,09 & B & 30,18 \\
MT6-4 & 173,14 & B & 29,75 \\
MT7-10 & 178,50 & B & 27,57 \\
MT1-4 & 187,78 & B & 23,81 \\
MT1-12 & 189,04 & B & 23,30 \\
MT4-8 & 189,38 & B & 23,16 \\
MT5-17 & 204,67 & B & 16,96 \\
Testemunha & 246,46 & A & - \\
C.V. & & & \\
\hline
\end{tabular}

${ }^{1} \mathrm{AACPD}$ - área abaixo da curva do progresso da doença

${ }^{2}$ Médias seguidas de mesma letra não diferem entre si pelo teste Scott-Knott, ao nível de 5\% de probabilidade.

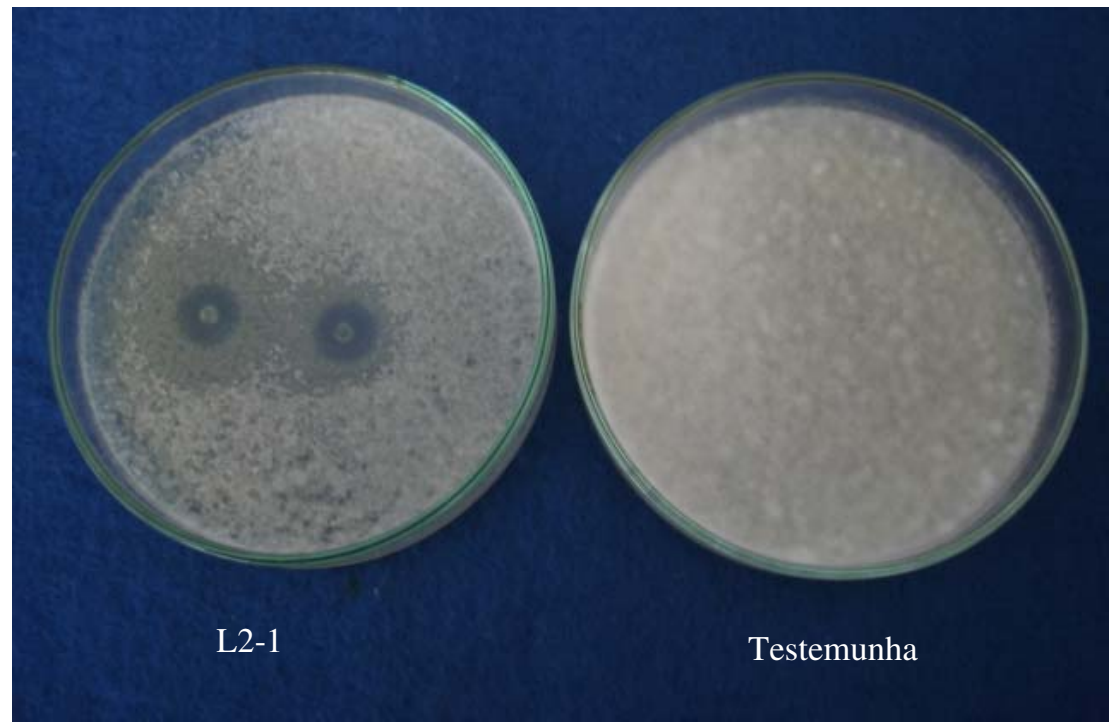

Figura 1 - Efeito do isolado L2-1 (Bacillus cereus) sobre o crescimento in vitro de Verticillium dahliae.

Kilic-Ekici \& Yuen (2004) verificaram que os isolados 89B-61 e WCS417r de Pseudomonas fluorescens não inibiram o crescimento micelial de Bipolaris sorokiniana e reduziram, significativamente, a severidade da doença em plantas de Festuca aurundinacea. Romeiro et al. (2005) verificaram que macromoléculas liberadas pelo isolado UFV101 Bacillus cereus não tiveram efeito antimicrobiano sobre os patógenos Alternaria solani, Pseudomonas syringae pv. tomato, Corynespora cassiicola, Xanthomonas camprestris pv. vesicatoria, $P$. syringae pv. syringae, $P$. corrugata, Ralstonia solanacearum e Clavibacter michiganensis pv. 
michiganensis, no entanto, proporcionaram a redução dos sintomas causados por A. solani, $P$. syringae pv. tomato, C. cassiicola e X. camprestris pv. Vesicatoria, no tomateiro.

Efeito dos isolados L2-1, L2-2, MT5-5, MT5-6 e MT5-11 de rizobactérias e acibenzolar-S-metil (ASM), no controle da ramulose e murcha de Verticillium em algodoeiro, em casa de vegetação

Os tratamentos com os isolados L2-2, MT5-11, L2-1 e MT5-5 reduziram a severidade da ramulose em $24,69 \%, 22,22 \%, 18,52 \%$ e $14,81 \%$, respectivamente, no entanto, nenhum deles diferiu, significativamente, da testemunha, enquanto o acibenzolar-S-metil (ASM) reduziu muito (80\%) a severidade da doença em relação à testemunha (Figura 2).

Quanto à murcha de Verticillium, os isolados L21, MT5-5 e MT5-11 e o acibenzolar-S-metil (ASM) proporcionaram redução da severidade da murcha de Verticillium em 6,51\%, 3,55\%, 1,09\% e 1,18\%. Entretanto, nenhum dos tratamentos diferiu significativamente da testemunha inoculada (Figura 3). Plantas tratadas com os isolados MT5-6 e L2-2 apresentaram maior severidade do que as plantas não tratadas. Resultados semelhantes foram obtidos por Berg et al. (2001) em processo de seleção de rizobactérias de diferentes hospedeiras de Verticillium dahliae. Estes autores verificaram que os isolados B E2 de Pseudomonas putida (rizosfera de morangueiro) e K15 de $P$. chlororaphis (rizosfera de batata) proporcionaram $11 \%$ e $6 \%$ de redução na incidência da doença, em plantas de morangueiro, no entanto o isolado R12 de Serratia plymuthica aumentou a incidência da doença.

Neste trabalho, foram selecionados, de 123 isolados de rizobactérias, os cinco isolados mais promissores na indução de resistência do algodoeiro à Xam. Quando testados contra os fungos C. gossypii var. cephalosporioides e Verticillium dahliae, não diferiram significativamente da testemunha inoculada. No entanto, quando aplicados em mudas de café, os cinco isolados reduziram significativamente a severidade da cercosporiose em relação à testemunha (AMARAL et al., 2006), sugerindo que tais isolados são mais eficientes em induzir resistência, em plantas de algodão e café, contra patógenos foliares. Os sintomas diretos da ramulose aparecem primeiramente em folhas novas, tanto na haste principal como nas laterais, na forma de manchas necróticas. No entanto, o fungo afeta o meristema apical provocando sua necrose, o que estimula o desenvolvimento dos brotos laterais que se transformam em galhos extranumerários, conferindo à planta o aspecto de envassouramento (CIA \& SALGADO, 1997), dificultando assim o seu controle. Silva et al. (2004b) observaram diferenças no grau de proteção

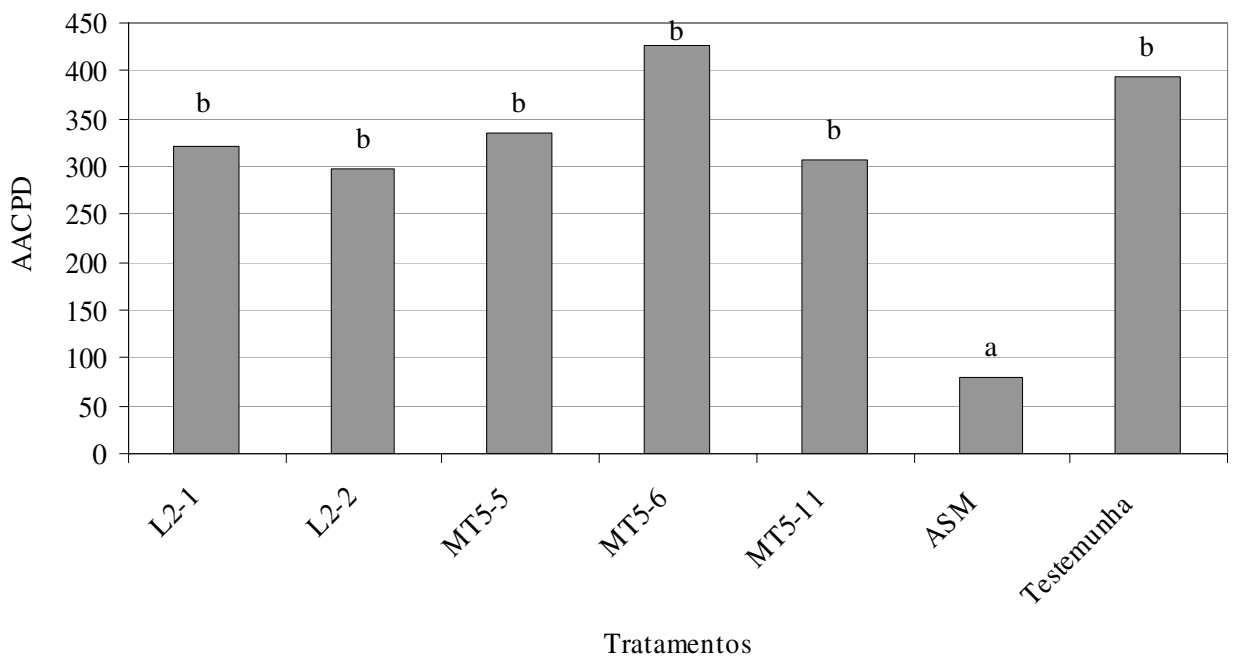

Figura 2 - Efeito dos isolados L2-1, MT5-5 e MT5-6 (Bacillus cereus), L2-2 (Achromobacter xylosoxidans) e MT5-11 (Brevibacterium sp.) de rizobactérias e do acibenzolar-S-metil (ASM), na redução severidade (AACPD) da ramulose. Médias seguidas de mesma letra não diferem entre si pelo teste Tukey, ao nível de 5\% de probabilidade $(\mathrm{CV}=21,73)$. $\mathrm{AACPD}=$ área abaixo da curva de progresso da doença. 
proporcionado por três isolados de rizobactérias (B101R, B212R e A068R), previamente selecionados como indutores de resistência sistêmica, em tomateiro, à Pseudomonas syringae pv. tomato, contra Alternaria solani, Stemphilium solani e Oidium lycopersici, sendo que apenas o isolado B101R (Bacillus cereus) reduziu a intensidade das três doenças. Segundo os autores, a defesa induzida por microrganismos em plantas pode apresentar níveis variáveis de eficiência em suprimir o ataque de patógenos, dependendo da habilidade deste em evitar as defesas ativadas do hospedeiro. A não especificidade da resistência induzida é uma característica almejada por pesquisadores e tem mostrado resultados positivos. Silva et al. (2004a) verificaram que a microbiolização de sementes com o isolado de rizobactéria Bacillus cereus, combinada ou não com aplicações do fungicida Chlorotalonil, reduziu a severidade das doenças causadas por Alternaria solani, Phytophthora infestans e Septoria lycopersici em condições de campo. Hoffland et al. (1996) confirmaram a não especificidade da ISR após a microbiolização de sementes de rabanete com o isolado WCS417 de P. fluorescens. Os autores observaram a redução da incidência da murcha causada por Fusarium oxysporum f. sp. raphani, bem como a redução na severidade de Alternaria brassicicola e Pseudomonas syringae pv. tomato. Estes resultados vislumbram o uso da resistência sistêmica induzida por rizobactérias, como uma ferramenta adicional no manejo integrado de doenças de plantas. Além disso, resultados promissores têm sido obtidos com a utilização de misturas compatíveis de isolados de rizobactérias, na indução de resistência de plantas. Jetiyanon \& Kloepper (2002) verificaram que um isolado (IN937a) e quatro misturas compatíveis de rizobactérias promoveram supressão significativa dos patógenos Ralstonia solanacearum, Rhizoctonia solani, Colletotrichum gloeosporioides e $\mathrm{CMV}$ - cucumber mosaic virus.

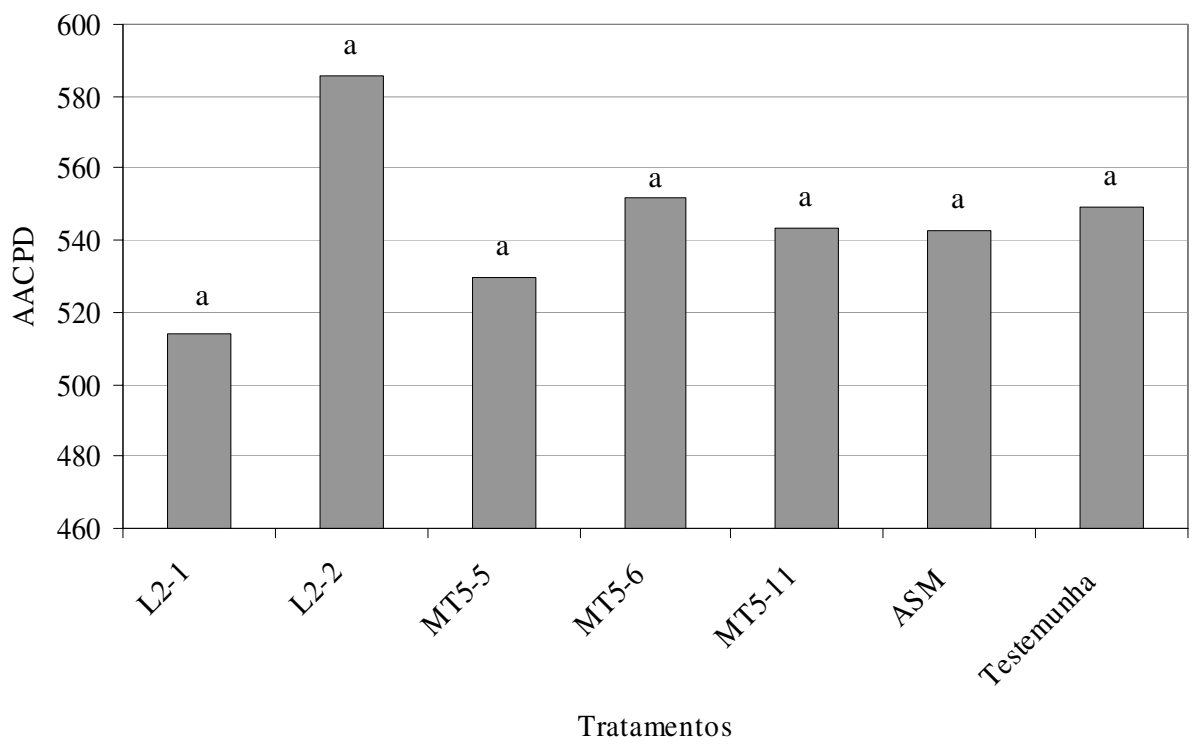

Figura 3 - Efeito dos isolados L2-1, MT5-5 e MT5-6 (Bacillus cereus), L2-2 (Achromobacter xylosoxidans) e MT5-11 (Brevibacterium sp.) de rizobactérias e do acibenzolar-S-metil (ASM), na redução da severidade (AACPD) da murcha de Verticillium. Médias seguidas da mesma letra não diferem entre si pelo teste Tukey, ao nível de 5\% de probabilidade $(\mathrm{CV}=17,45)$. AACPD = área abaixo da curva de progresso da doença. 


\section{CONCLUSÕES}

Os isolados L2-1, MT5-5 e MT5-6 (Bacillus cereus), L2-2 (Achromobacter xylosoxidans) e MT5-11 (Brevibacterium sp.) de rizobactérias reduziram a severidade da mancha angular do algodoeiro.

Nenhum dos isolados testados reduziu a severidade da ramulose e da murcha de Verticillium do algodoeiro.

\section{AGRADECIMENTOS}

Os autores agradecem à Fundação de Apoio à Pesquisa de Minas Gerais - FAPAMIG, pelo financiamento do projeto (CAG 1081/02) e concessão da bolsa de Pósdoutorado Júnior à primeira autora, e ao Conselho Nacional de Desenvolvimento Científico e Tecnológico - CNPq, pela concessão das bolsas de Produtividade e Iniciação Científica.

\section{REFERÊNCIAS BIBLIOGRÁFICAS}

AMARAL, D. R.; RESENDE, M. L. V.; ZACARONI, A. B.; ISHIDA, A. K. N.; RIBEIRO JÚNIOR, P. M.; SOUZA, R. M.; PÁDUA, M. A. Efeito de isolados e extratos de rizobactérias no controle da cercosporiose do cafeeiro. Fitopatologia Brasileira, Brasília, v. 31, p. 333, ago. 2006. Suplemento.

ARYA, S.; PARASHAR, R. D. Biological control of cotton bacterial blight with phylloplane bacterial antagonists. Tropical Agriculture, Trinidad, v. 79, n. 1, p. 51-55, Jan. 2002.

BERG, G.; FRITZE, A.; ROSKOT, N.; SMALLA, K. Evaluation of potential biocontrol rhizobacteria from different host plants of Verticillium dahliae Kleb. Journal of Applied Microbiology, [S.1.], v. 91, p. 963-971, 2001.

BUGBEE, W. M.; PRESLEY, T. J. A rapid inoculation technique to evaluate the resistance o cotton to Verticillium albo-atrum. Phytopathology, Saint Paul, v. 57, p. 1264, 1967.

CASSETARI NETO, D.; MACHADO, A. Q. Doenças do algodoeiro: diagnose e controle. Cuiabá: UFMT, 2000. 47 p.

CIA, E.; SALGADO, C. L. Doenças do algodoeiro (Gossypium spp.). In: KIMATI, K.; AMORIM, L.; BERGAMIN FILHO, A.; CAMARGO, L. E. A.; REZENDE, J. A. M. (Eds.). Manual de fitopatologia. 3. ed. São Paulo: Agronômica Ceres, 1997. v. 2, cap. 6, p. 33-48.
COSTA, A. S. Investigação sobre a ramulose. Campinas: Instituto Agronômico de Campinas, 1941. (Relatório, 1012).

HOFFLAND, E.; HAKULINEN, J.; PELT, J. A. van. Comparison of systemic resistance induced by avirulent and nonpathogenic Pseudomonas species. Phytopathology, Saint Paul, v. 86, n. 7, p. 757-762, July 1996.

ISHIDA, A. K. N. Resistência induzida por rizobactérias e acibenzolar-S-metil (ASM) no controle da mancha angular (Xanthomonas axonopodis pv. malvacearum) do algodoeiro. 2004. 130 p. Tese (Doutorado em Fitopatologia) - Universidade Federal de Lavras, Lavras, 2004.

JETIYANON, K.; KLOEPPER, J. W. Mixtures of plant growth-promoting rhizobacteria for induction of systemic resistance against multiple plant diseases. Biological Control, San Diego, v. 24, n. 3, p. 285-291, July 2002.

JULIATTI, F. C.; RUANO, O. Algodão (Gossypium hirsutum L.): controle de doenças. In: VALE, F. X. R.; ZAMBOLIM, L. (Eds.). Controle de doenças de plantas. Viçosa: UFV; Brasília, DF: Ministério da Agricultura e do Abastecimento, 1997. v. 2, cap. 12, p. 555-610.

KADO, C. I.; HESKETT, M. G. Selective media for isolation of Agrobacterium, Corynebacterium, Erwinia, Pseudomonas and Xanthomonas. Phytopathology, Saint Paul, v. 60, n. 6, p. 969-976, June 1970.

KILIC-EKICI, O.; YUEN, G. Y. Comparison of strains of Lysobacter enzymogenes and PGPR for induction of resistance against Bipolaris sorokiniana in tall fescue. Biological Control, San Diego, v. 30, n. 2, p. 446-455, 2004.

KNOESTER, M.; PIETERSE, C. M.; BOL, J. F.; LOON, L. C. van. Systemic resistance in Arabidopsis induced by rhizobacteria requires ethylene-dependent signaling at the site of application. Molecular Plant-Microbe Interactions, Saint Paul, v. 12, n. 8, p. 720-727, Aug. 1999.

LAZO, G. R.; GABRIEL, D. W. Conservation of plasmid DNA sequences and pathovar identification of strains of Xanthomonas campestris. Phytopathology, Saint Paul, v. 77, n. 3, p. 448-453, Mar. 1987.

LOON, L. C. van; BAKKER, P. A. H. M.; PIETERSE, C. M. J. Systemic resistance induced by rhizosphere bacteria. Annual Review of Phytopathology, Palo Alto, v. 36, p. 453483, 1998. 
MAUCH-MANI, B.; MÉTRAUX, J. P. Salicylic acid and systemic acquired resistance to pathogen attack. Annals of Botany, London, v. 82, n. 5, p. 535-540, Nov. 1998.

RAMAMOORTHY, V.; VISWANATHAN, R.; RAGUCHANDER, T.; PRAKASAM, V.; SAMIYAPPAN, R. Induction of systemic resistance by plant growth promoting rhizobacteria in crop plants against pest and diseases. Crop Protection, Oxford, v. 20, n. 1, p. 1-11, Feb. 2001.

ROMEIRO, R. S.; LANNA FILHO; VIEIRA JÚNIOR, J. R.; SILVA, H. S. A.; BARACAT-PEREIRA, M. C.; CARVALHO, M. G. Macromolecules released by a plant growthpromoting rhizobacterium as elicitors of systemic resistance in tomato to bacterial and fungal pathogens. Journal of Phytopathology, Saint Paul, v. 153, n. 2, p. 120-123, 2005.

SAFIYAZOV, J. S.; MANNANOV, R. N.; SATTAROVA, R. $\mathrm{K}$. The use of bacterial antagonists for the control of cotton diseases. Field Crops Research, Amsterdam, v. 43, n. 1, p. 51-54, Sept. 1995.

SHANER, G.; FINNEY, R. The effect of nitrogen fertilization on the expression of slow-mildewing resistance in Knox Wheat. Journal of Phytopathology, Saint Paul, v. 67, n. 8, p. 1051-1056, 1977.
SIDHU, G. S.; WEBSTER, J. M. The use of aminoacid fungal auxotrophs to study the predisposition phenomena in the root-knot: wilt fungus disease complex. Physiological Plant Pathology, London, v. 11, n. 2, p. 117-127, 1977.

SILVA, H. S. A.; ROMEIRO, R. S.; CARRER FILHO, R.; PEREIRA, J. L. A.; MIZUBUTI, E. S. G.; MOUNTEER, A. Induction of systemic resistance by Bacillus cereus against tomato foliar diseases under field conditions. Journal of Phytopathology, Saint Paul, v. 152, p. 371-375, 2004a.

SILVA, H. S. A.; ROMEIRO, R. S.; MACAGNAN, D.; HALFELD-VIEIRA, B. A.; PEREIRA, M. C. B.; MOUNTEER, A. Rhizobacterial induction of systemic resistance in tomato plants: non-specific protection and increase in enzyme activities. Biological Control, San Diego, v. 29, n. 2, p. 288-295, Feb. 2004b.

STEINER, U.; SCHÖNBECK, F. Induced disease resistance in monocts. In: HAMMERSCHMIDT, R.; KUC, J. (Eds.). Induced resistance to disease in plants: developments in plant pathology. Dordrech: Kluwer Academic, 1995. p. 86-110.

VAUTERIN, L.; HOSTE, B.; KERSTERS, K.; SWINGS, J. Reclassification of Xanthomonas. International Journal Systematic Bacteriology, Washington, v. 45, n. 3, p. 472489, June 1995. 